\title{
ADAPTIVE PI SPEED CONTROLLER FOR A UNIVERSAL MOTOR
}

\author{
Dina A. Elkady, Haitham Z. Azazy, Arafa S. Mansour and Shokry S. Shokrallah \\ Electrical Engineering Department, Faculty of Engineering, Shebin El-Kom, \\ Menoufiya University, Egypt.
}

\begin{abstract}
In this paper, Adaptive gain scheme of Proportional-Integral (PI) controller to optimize the parameters of the PI for speed control of a universal motor is presented. The PI gains are allowed to vary on-line and automatically in order to avoid tedious task in manual control which eliminates the problems faced by the conventional PI controller. For conventional PI controller, the PI gains are optimized by trial and error method. In adaptive PI controller, their gains are allowed to vary on-line with motor speed and load variations. The performance of the presented controller is tested through a wide range of speeds as well as with load variations through simulation using MATLAB/SIMULINK and experimental results using DSP 1104. The simulation and experimental results show that the adaptive PI controller can be efficiently used for tuning parameters of the PI controller under distinct operation conditions.

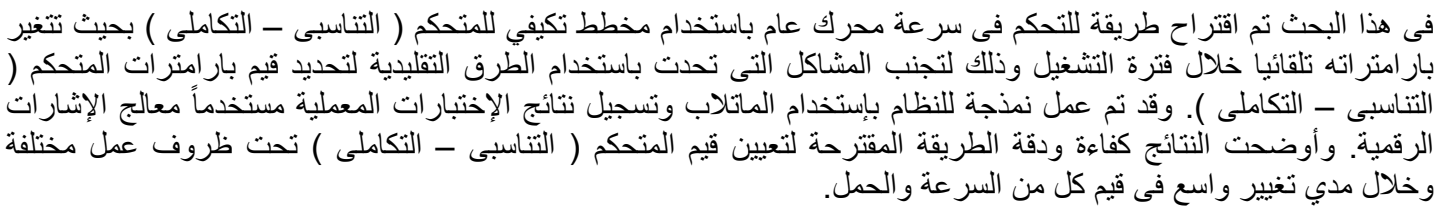

keywords: Adaptive PI Controller, Proportional-Integral (PI), AC chopper, universal motor.

\section{INTRODUCTION}

Universal motors are widely used in household appliances like food processors, vacuum cleaners, sewing machines and most domestic appliances because it is cost effective in respect of volume/power and it has a good torque response [1]. It also has a high starting torque and possibility to be fed with direct current, so this machine is as well used as starter motor for engines.

The speed of a universal motor can be very high, typically in the range of 5000-20000 rpm. The speed is entirely dependent on the load and the supply voltage. Without load, a universal motor may reach dangerously high speeds [2].

AC chopper with speed feedback is used to achieve the properties of universal motor. In addition, a control system with low cost is desired [3-5].

AC choppers that change the rms value of $\mathrm{AC}$ voltage feeding a load from a constant voltage AC source are in widespread use for purposes of power control in industrial applications such as heating, lightning and ac motor speed control [2-6]. There are some kinds of AC voltage regulators such as auto-transformer and thyristor phase-controlled voltage regulator. Autotransformer has a large size and its voltage regulating speed is low. The thyristor phase controlled voltage regulator has a relatively fast response compared with the auto-transformer [7]. However, the large amount of the low-order harmonic currents is the major problems. Large passive filter is needed and the system cost is increased.

These problems can be solved by using PWM AC chopper. This chopper has some advantages such as fast dynamics and small size filter. Three switches [89] and four switches [10-14] AC chopper are presented in the previous presented papers. In these researches, the switching patterns are critical and an alternate path has to be established in dead-time period. DC regenerative snubber capacitor $[10,15-16]$ was used to realize safe commutation and enhance efficiency. However, these converters still have complex topologies and control strategies. These commutation strategies are related to the phase of input voltage and input current. As a result, these converters are prone to be disturbed and hard to be implemented. In addition, there are voltage spikes across the power switches 
during the commutation process. The previous researches have not given enough consideration to the protection of the power switches. Thus, the switching devices are easy to be destroyed for lack of protection.

During the past decades, the process control techniques in the industry have made great advances. Numerous control methods, neural control, and genetic fuzzy PID controller based on adaptive gain scheduling for load frequency control was proposed in [17-18]. Among them, the best known is the proportionalintegral (PI) controller. PI controller has been applied in feedback loop mechanism and extensively been used in industrial process control. Easy implementation of PI controller, made it more popular in the system control applications. It tries to correct the error between the measured outputs and desired outputs of the process in order to improve the transient and steady state responses as much as possible [19]. In one hand, PI controller appear to has an acceptable performance in the most of systems, but sometimes there are functional changes in system parameters that need an adaptive based method to achieve more accurate response. The Ziegler-Nichols tuning formula is perhaps the best known tuning method [20]. Unfortunately, it has been quite difficult to properly tune the PI gains because many industrial plants are often burdened with problems such as high order, time delays, and nonlinearities. In addition fixed gain feedback controllers fail to provide best control performance over a wide range of off-nominal operating conditions.

To reduce the complexity of tuning PI parameters by the traditional approach, many random search methods i.e. simulated annealing (SA), genetic algorithm (GA), bees algorithm (BA), ant-colony optimization (ACO) and particle swarm optimization (PSO), have recently received much interest for achieving high efficiency and searching global optimal solution [21-24]. Nevertheless, these kinds of control strategy are difficult to be implemented due to the large amount of floating-point computation, which means an increase in the sampling period.

In this paper, a buck type $\mathrm{AC}$ chopper voltage regulator is proposed. The switch is composed of an Insulated Gate Bipolar Transistor (IGBT) and a fast recovery diode rectifier. Only two switching devices are used instead of three or four switches in the previous presented plans. Thus, cost is reduced and commutation process is highly simplified. Also, adaptive PI controller for a universal motor drive is presented. The adaptive PI controller is able to achieve stable and robust control performance to the system [25]. The adaptive PI speed controller is tuning with operating conditions. Their gains are allowed to vary on-line and therefore eliminate the problem by the conventional PI controller. Simulink model is established on Matlab/Simulink to test the universal motor drive system with the different speed controllers under different operating conditions. Experimental system is built to examine and assess the performance of the adaptive PI controller.

\section{THE SYSTEM DESCRIPTION}

Figure 1 shows the configuration of a single phase AC chopper fed a universal motor. It consists of two power switches, one switch $S_{1}$ is connected in series and the second $S_{2}$ is in parallel with the load. The series switch regulates the power to the load, while the parallel switch provides the freewheeling path to discharge the stored energy when the series switch is turned off.

There are two modes of operation. Mode 1 is occurred when the switch $S_{1}$ is on and $S_{2}$ is off, while mode 2 is occurred when the switch $S_{2}$ is on and $S_{1}$ is off.

Mode 1: In this mode the main switch is on and the freewheeling switch is off. The differential equations that describe this mode are:

$$
\begin{aligned}
& \begin{array}{l}
v_{m} \\
=v_{s}-l_{s}\left(\frac{d i_{s}}{d t}\right)-i_{s} r_{s}
\end{array} \\
& v_{m}=l_{m}\left(\frac{d i_{m}}{d t}\right)+i_{m} r_{m} \\
& +e \\
& \text { e } \\
& =k_{m} \omega_{m} i_{m} \\
& v_{S} \\
& =V_{\text {max }} \sin \omega t \\
& T_{l}=J\left(\frac{d \omega_{m}}{d t}\right)+B \omega_{m} \\
& +T_{L} \\
& T_{e}= \\
& K_{m} i_{m}^{2}
\end{aligned}
$$

Mode 2: In this mode the main switch is off while the freewheeling switch is on. The differential equations describing this mode are given by:

$$
\begin{aligned}
& \begin{array}{l}
v_{m} \\
=0
\end{array} \\
& \begin{array}{r}
0=l_{m}\left(\frac{d i_{m}}{d t}\right)+i_{m} r_{m} \\
+e
\end{array} \\
& \begin{array}{l}
e \\
=k_{m} \omega_{m} i_{m}
\end{array}
\end{aligned}
$$


$T_{l}=J\left(\frac{d \omega_{m}}{d t}\right)+B \omega_{m}$

$T_{e}$

$=k_{m} i_{m}^{2}$

Where:

$B$ : Viscous friction coefficient.

e: Motor Back emf.

$J$ : System moment of inertia.

$i_{s}$ : Instantaneous supply current.

$i_{m}$ : Instantaneous motor current.

$K_{m}$ : Back emf constant.

$l_{S}, r_{S}$ : Supply inductance and resistance.

$l_{m}, r_{m}$ : Motor inductance and resistance.

$T_{e}$ : Electromagnetic torque.

$T_{l}$ : Load torque.

$v_{m}$ : Motor input voltage.

$v_{s}$ : Supply voltage.

$V_{\text {max }}$ : Maximum value of the supply input voltage. $\omega_{m}$ : Motor angular speed.

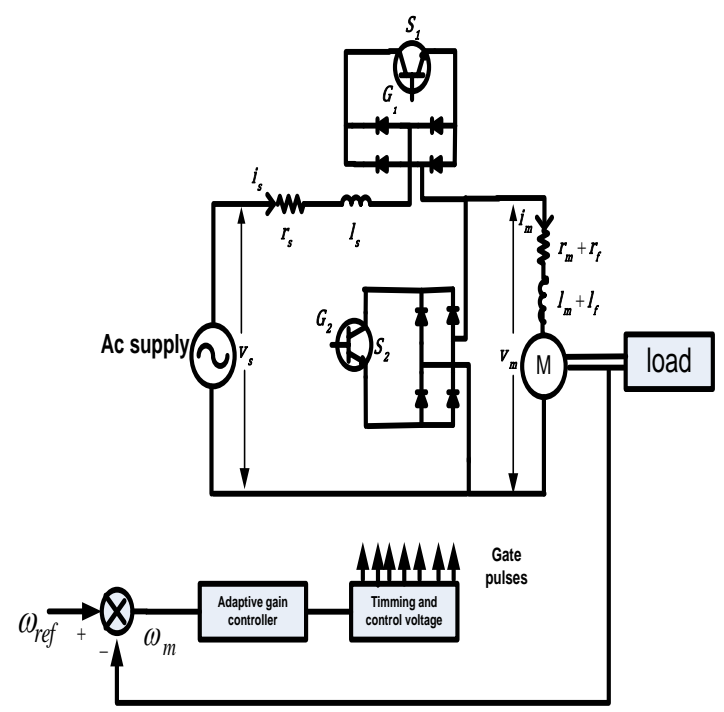

Fig. 1 single phase Ac chopper fed universal motor

\section{SPEED CONTROL SCHEME of UNIVERSAL MOTOR}

\section{A. Conventional PI Controller}

PI controller is a good controller in the field of machine control, because the PI controller is simple in structure and is easy to use, but the problem is the mathematical model of the plant must be known in order to solve the overall system. Generally, the speed error as follows in equation (12), which is the difference between reference speed and actual speed, is given as input to the controllers.

$e(t)$

$=w_{r}^{*}(t)$

$-w_{r}(t)$.

The conventional fixed PI speed controller can be constructed as shown in Fig. 2, and the differential equation can be written as:

$T^{*}(t)$

$=K_{p} e(t)$

$+K_{i} \int e(t) d t$

Where $K_{p}$ and $K_{i}$ are The PI controller gains. $K_{p}$ is the proportional gain which has the effect on reducing the rise time, but not for the steady-state, and $K_{i}$ is the integral gain which eliminates the steady-state error. These are tuned at rated condition and have these values along with the different operating conditions.

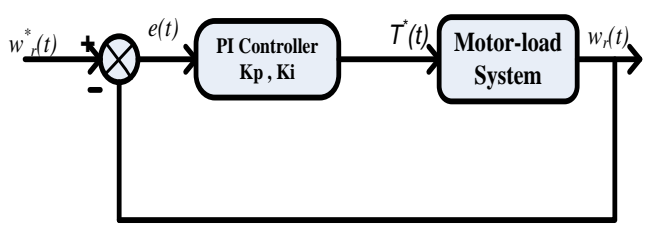

Fig. 2 Speed controller for a conventional fixed PI

\section{B. Adaptive PI Speed Controller}

Adaptive PI controller method is applied for on-line tuning of PI controller in presence of set point changes. It is offers a robust performance and reduced amount of computation. The structure of this method has the ability of on-line tuning of the PI controller with respect to time [26]. In this method, very easy to implement in practice since an existing PI controller is tuned automatically as shown in Fig. 3. The adaptive PI controller output is given by [19]:

$T^{*}(t)$

$=K_{p}(t) e(t)+K_{i}(t) \int e(t) d t$

where $K_{p}(t)$ is the proportional gain, and $K_{i}(t)$ is the integral gain. These gains are functions of the speed error, $e(t)$. The gain $K_{p}(t)$ is expressed as a function of speed error as follows:

$\begin{aligned} K_{p}(t)=K_{p(\max )} & -\left(K_{p(\max )}\right. \\ & \left.-K_{p(\min )}\right) e^{-[k e(t)]}\end{aligned}$ 
Where $k$ is a constant which decides the rate at which $K_{p}(t)$ varies between maximum and minimum values of the proportional gain. A large proportional gain $K_{p(\max )}$ is used to speed up the transient response when the speed error $e(t)$ is large and when the error becomes small; a minimum proportional gain $K_{p(\min )}$ is used to eliminate overshoots and oscillations. The integral gain $K_{i}(t)$ is expressed as a function of speed error signal $e(t)$ and is given by.

$K_{i}(t)=$

$K_{i(\max )} e^{-[k e(t)]}$

Under steady state condition when the speed error $e(t)$ is small, large integral gain is used to overcome the steady state error. When the error signal is large, a small integral gain is used to eliminate the undesirable oscillation and overshoot.

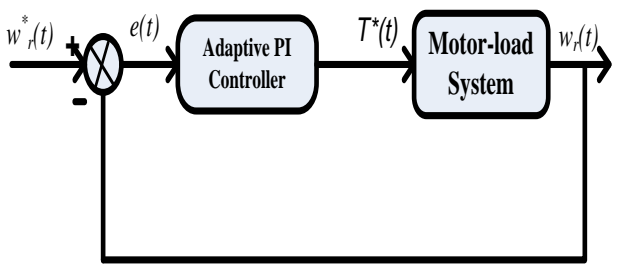

Fig. 3 Adaptive PI speed controller.

\section{SIMULATION RESULTS}

The control algorithm of the adaptive PI control methods has been developed and simulated using the MATLAB/SIMULINK software. The system parameters are reported in the appendix. The parameters of the actual machine that is used to accomplish the experimental setup are given in Table 1 . These parameters are exploited to implement the machine in the SIMULINK field for ascertaining simulated close to the experimental ones in order to verify the accuracy of the presented controller. The gain values of speed controller are shown in Tables 2 and 3 .

\section{A. During Speed Variations}

Regarding the results shown in Fig. 4, with load torque equal to the motor rated torque, the stability of the universal motor drive system with the different controllers is tested during step changes in the motor reference speed. It is evident that the presented controller as shown in Fig. 4, gives a good performance and zero steady state error in comparison with the conventional PI. It is clear that the adaptive PI controller exhibits superior performance in comparison with fixed PI controller which suffers from overshoots and large settling time.

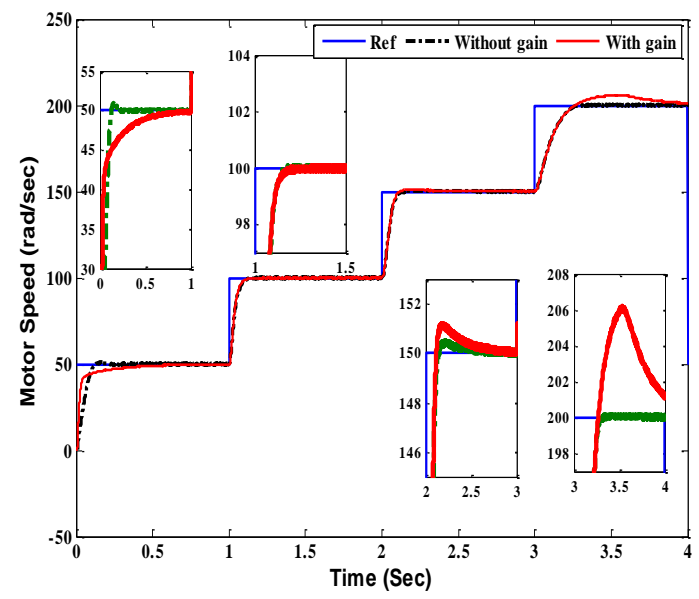

(a)

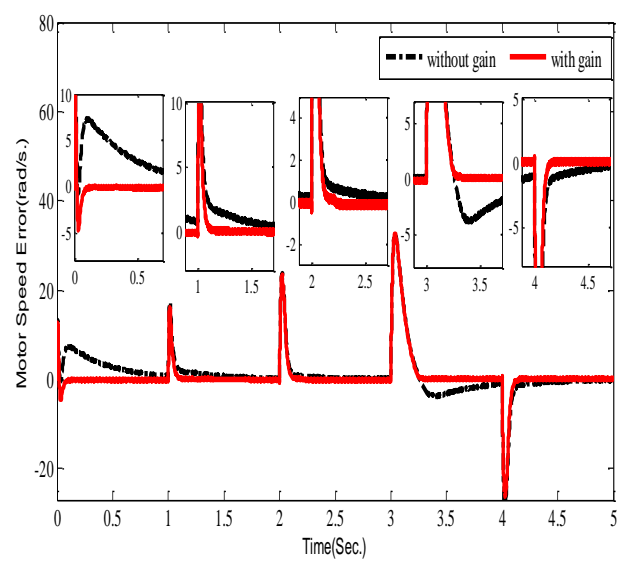

(b)

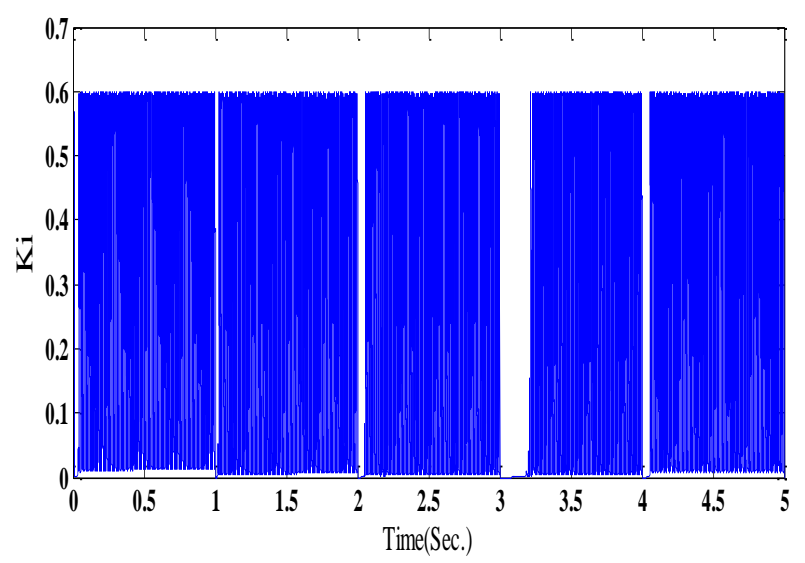

(c) 


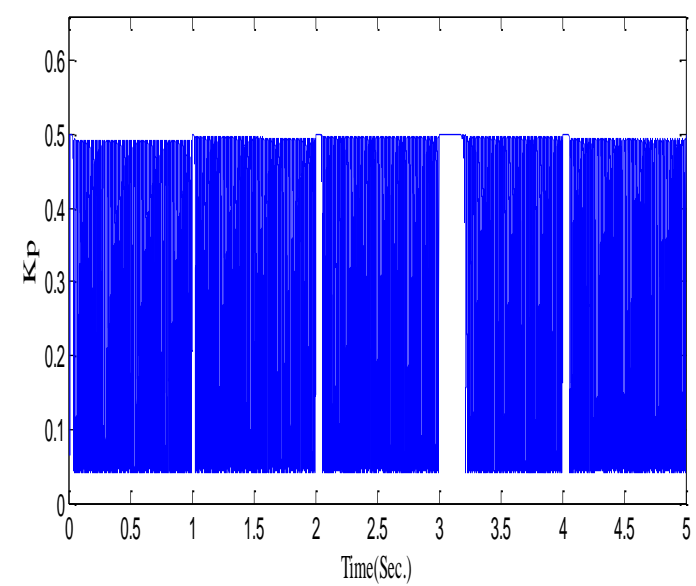

(d)

Fig.4 Simulation results during speed variations of the (a) motor Speed, (b) motor Speed Error, (c) variation of $K_{i}$ and (d) variation of $K_{p}$.

\section{B. During Load Torque Disturbances}

The simulation results during load disturbances of the motor speed, motor speed error, variation of $K_{p}$ and variation of $K_{i}$ are presented in Fig. 5. With the motor reference speed is equal to $150 \mathrm{rad} / \mathrm{sec}$, step changes in the load torque are introduced as shown in Fig. 5(c). It is clear from Fig. 5 that the adaptive PI controller has a good performance in tracking of the system. Also, the steady state error is zero and a good transient response can be achieved comparing with the conventional PI.

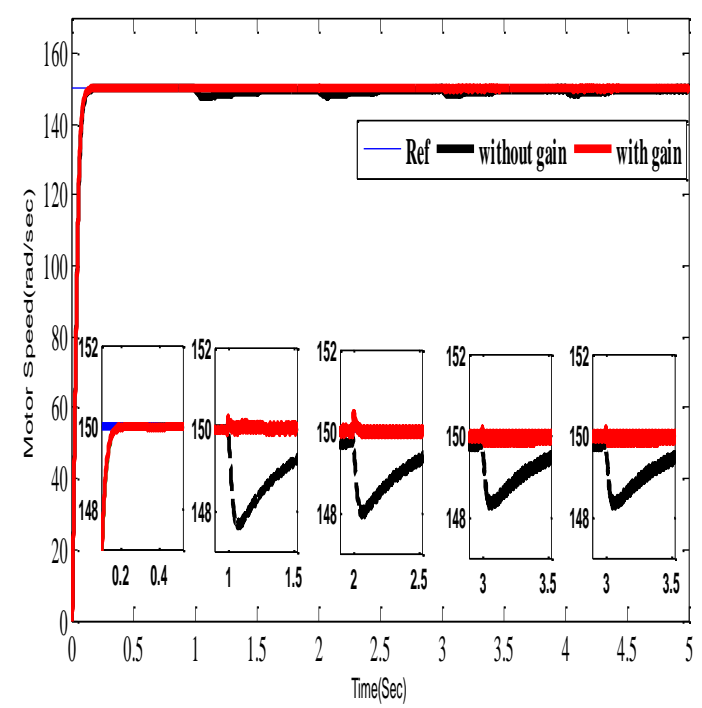

(a)

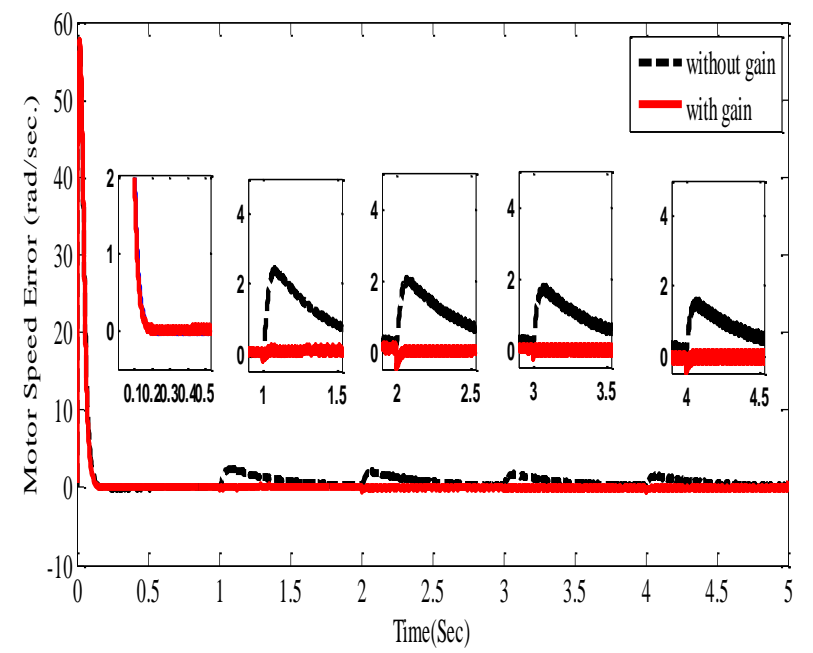

(b)

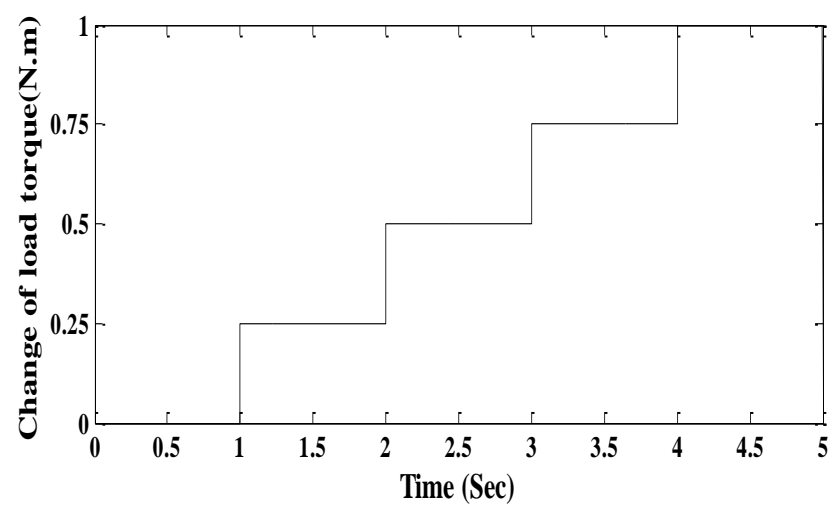

(c)

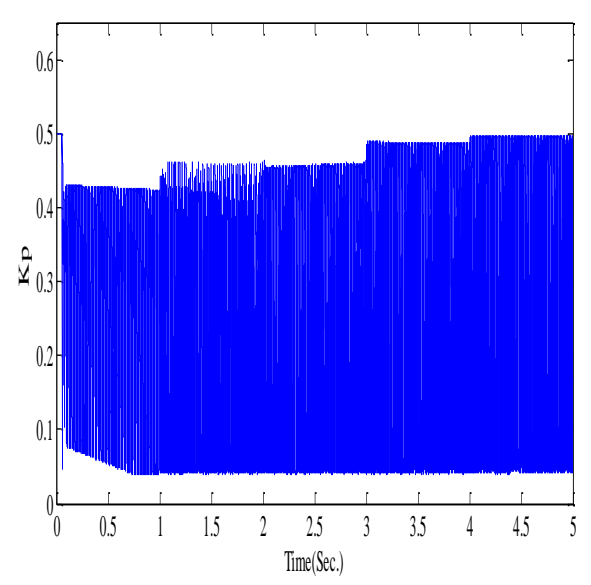

(d) 

$" \prime$

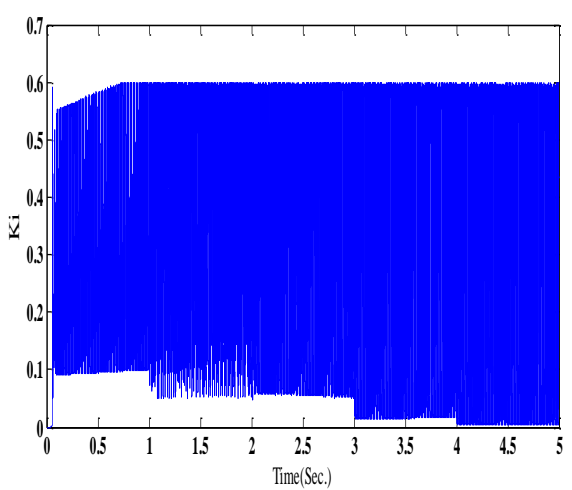

(f)

Fig. 5 Simulation results during load disturbances of the (a) motor speed, (b) motor speed error, (c) change of load torque (d) variation of $K_{p}$ and (f) variation of $K_{i}$.

\section{EXPERIMENTAL RESULTS}

The experimental setup is carried out in laboratory by a $d S P A C E D S 1104$ system with $I / O$ card for real-time control. An interface board was built to receive the gate-drive signals, isolated them and connected to the two switches which were implemented using integrated IGBTs $100 \mathrm{~A}$. A photograph of the experimental system is shown in Fig. 6. The experimental results have been presented under different operating conditions including speed variations and load torque disturbances using the adaptive PI controller.

\section{A. During Speed Variations}

The experimental results of the motor speed and motor current by using the adaptive PI controller are shown in Fig. 7. It is noted that, the overall dynamic performance of the motor when operated with adaptive PI controller is better than the hand tuning. The steadystate error of the speed response is zero, the overshoot and undershoot is low when the motor speed changes.

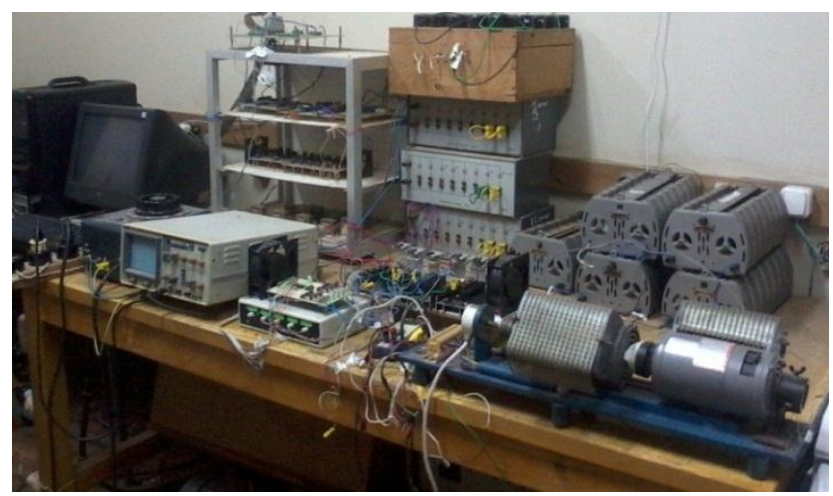

Fig.6 General view of the experimental setup

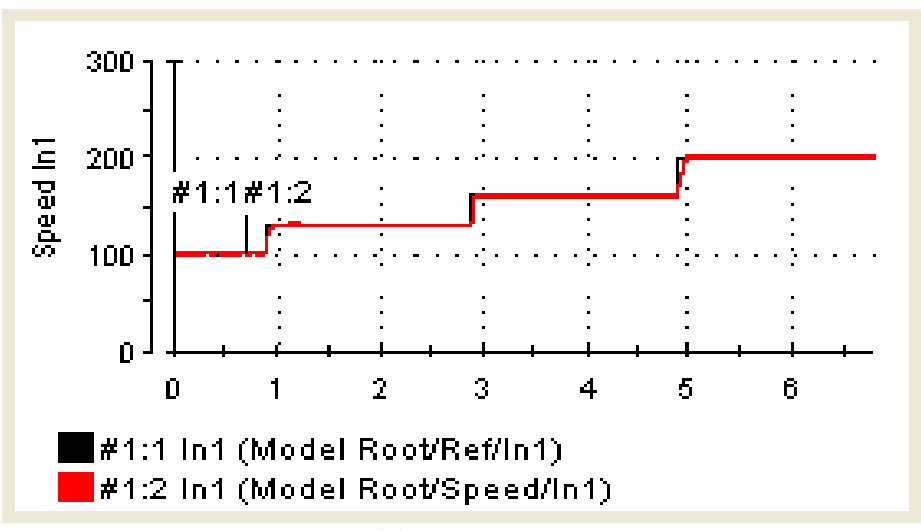

(a)

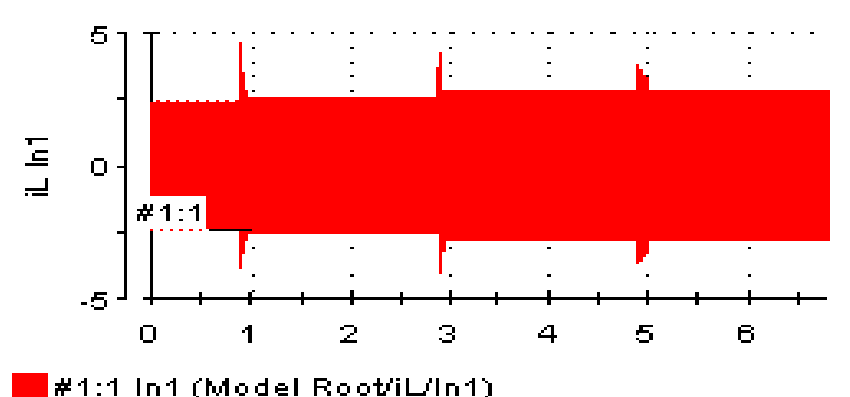

\#1:1 In 1 (Model Root/iLin1)

(b)

Fig. 7 Experimental results during speed variations of the (a) motor speed and (b) motor current.

\section{B. During Load Disturbances}

Figure 8, shows the experimental results of the motor speed and motor current during load disturbances. The performance of a universal motor has been examined during step change in the load torque to show the effectiveness and superiority of the adaptive PI controller.

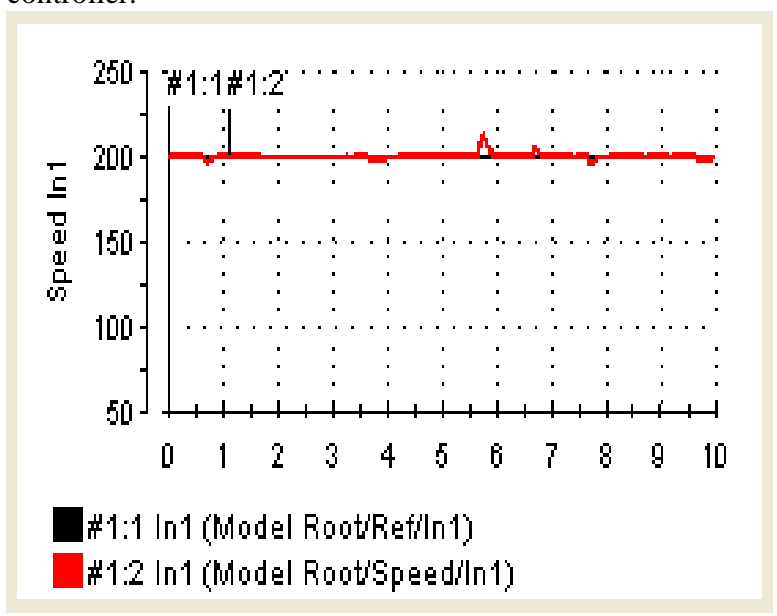

(a) 


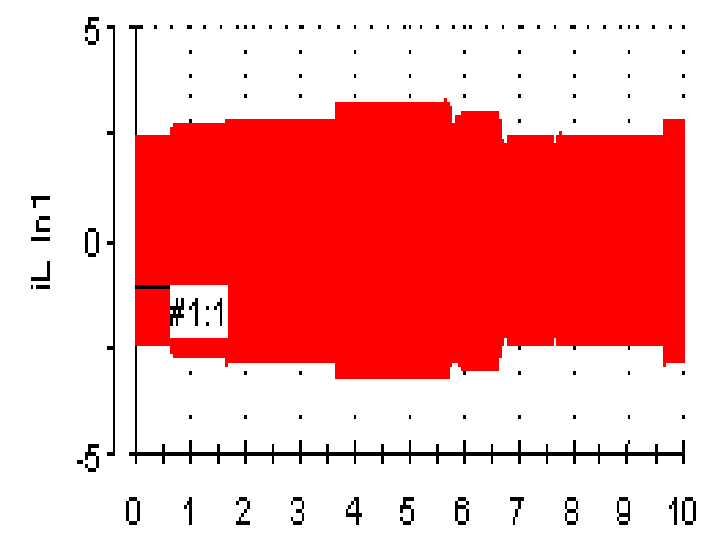

\#1:1 In1 (Model Rootílilnil)

(b)

Fig. 8 Experimental results during load disturbances of the

\section{CONCLUSIONS}

(a) motor speed and (b) motor current.

In this paper, the performance of the adaptive PI controller in comparison with the conventional PI controller has been examined and assessed by simulation and experimental results. Different operating conditions during speed variations and load torque disturbances have been used for this comparison. It has been evident that the presented controller method has been offered a superior performance in comparison with the conventional fixed PI controller. It has been obvious that the speed response with fixed PI controller suffers from overshoots and large settling time. However, the adaptive PI controller exhibits good performance without any overshoot. The superiority of adaptive PI controller has been proved and confirmed under load disturbances and also, it has been observed that the speed recovers quickly and the speed dip is low with adaptive PI controller comparing with the fixed PI controller. The simulation and experimental results have been shown the effectiveness of the presented controller method.

\section{REFERENCES}

[1] P. C. Sen, "Principles of electrical machines and power electronics", IEEE Press, second edition, ISBN 978-0-471-20812-9, July 2002.

[2] P. F. Ryff, D. Platnick and J. A. Karnas, "Electrical machines and transformers, Principles and applications", First Edition, ISBN 0-13-247222-8, New Jersey, January 1987.
[3] G. Choe, A. K. Wallace and M. H. Park, "An Improved PWM Technique for AC Choppers", IEEE Transactions on Power Electronics, Vo1. 4, No.4, PP 496-505, October 1989.

[4] T. Nishimura, M. Nakaoka, and T. Maruhashi, "Reduction of Vibration and Acoustic Noise in Induction Motor Driven by Three Phase PWM AC Chopper Using Static Induction Transistors", IEEE Transactions on Power Electronics, Vo1. 4, No. 3, PP. 313-318, July 1989.

[5] D. H. Jang and G. H. Choe, "Improvement of Input Power Factor in AC Choppers Using Assymetrical PWM Technique", IEEE Transactions on Industrial Electronics, Vol. 42, No. 2, PP. 179-185, April 1995.

[6] D. H. Jang, G. H. Choe and M. Ehsani, "A symmetrical PWM Technique with Harmonic Elimination and Power Factor Control in AC Choppers", IEEE Transactions on Power Electronics, Vol. 10, No. 2, PP.175-18, March 1995.

[7] B. M. E., H. M. H. "Effects of Source Voltage Harmonic Distortion on Power Factor Compensation in Triac Controlled AC Chopper Circuits", IEEE International Conference on Power Electronics, Drives and Energy Systems (PEDS), Vol. 2, PP. 1199-1204, November 2005.

[8] N. A. Ahmed, K. Amei, and M. Sakui, "A New Configuration of Single-Phase Symmetrical PWM AC Chopper Voltage Controller", IEEE Transactions on Industrial Electronics, Vol. 46, No. 5, PP. 942-952, October 1999

[9] N. A. Ahmed, K. Amei and M. Sakui, "Improved Circuit of AC Choppers for Single Phase System", IEEE International Conference on Power Conversion (PCC), Nagoya, Vol. 2, PP. 907-912, August 1997.

[10] T. Shinyama, M. Kawai, A. Torii and A. Ueda, "Characteristic of an AC Chopper Circuit with LC Filters in the Input and Output Side", Electrical Engineering in Japan, Vol. 155, No. 2, PP. 45-52, April 2006.

[11] B. H. Kwon, J. H. Youm and J. H. Choi, "Automatic voltage regulator with fast dynamic speed", IEEE Proceedings of Electrical Power Application, Vol. 146, No. 2, PP. 201-207, Mars 1999.

[12] J. H. Kim, B. D. Min, and B. H. Kwon, "A PWM Buck-Boost AC Chopper Solving the Commutation Problem", IEEE Transactions On Industrial Electronics, Vol. 45, No. 5, PP. 832-835, October 1998.

[13] T. Shinyama, A. Ueda, and A. Torii, "AC chopper using four switches", IEEE International 
[14] Conference on Power Conversion (PCC), Osaka, Vol. 3, PP. 1056-1060, April 2002.

[15] S. Polmai and E. Sugprajun, "Experiment on Instantaneous Value Voltage Control of a Single Phase AC Chopper", IEEE International Conference on Power Conversion (PCC), Nagoya, PP. 77-82, April 2007.

[16] B. H. Kwon and G. Y. Jeong, "Novel Line Conditioner With Voltage Up/Down Capability", IEEE Transactions on Industrial Electronics, Vol. 49, No. 5, PP. 1110-1119, October 2002.

[17] C. R. Geraldo, Sincero and A. J. Perin, "High Pressure Sodium Lamp High Power Factor Electronic Ballasts Using AC-AC Converters", IEEE Transactions on Power Electronics, Vol. 22, No. 3, PP. 804-814, May 2007.

[18] A. Kumar, A. Kumar and S. Chanana, "Genetic Fuzzy PID Controller Based on Adaptive Gain Scheduling for Load Frequency Control", IEEE International Conference on Power Electronics, Drives and Energy Systems (PEDES), India, PP. 18, December 2010

[19] A. G. Ram and S. A. Lincoln, "A Model Reference-Based Fuzzy Adaptive PI Controller for non-linear level process system", Journal of IJRRAS, Vol. 14, No. 2, February 2013.

[20] M. S. Zaky and E. M. Ismaeil, "Gain Scheduling Adaptive PI Control of Hybrid Stepper Motor Drives Stepper Motor Drives", International Middle-East Conference on Power Systems (MEPCON), Egypt, PP. 85-91, December 2010.

[21] J. G. Ziegler and N. B. Nichols, "Optimum settling for automatic controllers", Journal of Dynamic System, Measurement, and Control, Vol. 115, No. 2B, PP. 220-222, June 1993.

[22] R. A. Krohling and J. P. Rey, "Design of optimal disturbance rejection PID controller using genetic algorithm", IEEE Transactions on Evolutionary Computation, Vol. 5, No. 1, PP. 78-82, February 2001.

[23] S. P. Ghoshal, "Optimization of PID gains by particle swarm optimizations in fuzzy based automatic generation control", Electric Power Systems Research, Vol. 72, No. 1, PP. 203-212, January 2004.

[24] C. Ou and W. Lin, "Comparison between PSO and GA for parameters optimization of PID Controller", IEEE International Conference on Mechatronics and Automation (MAC), Luoyang, Henan, PP. 2471-2475, June 2006.

[25] K. O. Jones and A. Bouffet, "Comparison of bees algorithm, ant colony optimisation and particle swarm optimisation for PID controller tuning",
International Conference on Computer Systems and Technologies (CompSysTech'08), New York, PP. 1-6, June 2008.

[26] C. Chen, "A model-Based Direct adaptive PI Controller for nonlinear process control", Chemical engineering communications, Vol. 201, No. 9, PP. 1148-1172, May 2014.

[27] M. A. Movahed and A. M. Yazdani, "Application of Imperialist Competitive Algorithm in Online PI Controller" IEEE International Conference on Intelligent Systems, Modelling and Simulation (ISMS), Kuala Lumpur, PP. 83-87, January. 2011.

\section{APPENDIX}

The simulation and the experimental results are taken with the following specifications:

Table 1 The system parameters are as follows:

\begin{tabular}{|l|l|}
\hline Rated power & $1 / 3 \mathrm{HP}$ \\
\hline Rated voltage & $220 \mathrm{~V}$ \\
\hline Rated current & $2.6 \mathrm{~A}$ \\
\hline Stator resistance & $11 \Omega$ \\
\hline Armature inductance & $0.112 \mathrm{H}$ \\
\hline Rated speed & $2000 \mathrm{rpm}$ \\
\hline Moment of inertia & $0.0015 \mathrm{~kg} \cdot \mathrm{m}^{2}$ \\
\hline Rated torque & $1 \mathrm{~N} . \mathrm{m}$ \\
\hline Supply resistance & $1.1 \Omega$ \\
\hline Supply inductance & $0.0112 \mathrm{H}$ \\
\hline
\end{tabular}

Table 2 Gains of Conventional Fixed PI

\begin{tabular}{|c|c|}
\hline$K_{P}$ & 0.0545 \\
\hline$K_{I}$ & 0.12 \\
\hline
\end{tabular}

Table 3 Gains of Adaptive PI Speed Controller

\begin{tabular}{|c|c|}
\hline$K_{P}(\max )$ & 0.5 \\
\hline$K_{P}(\min )$ & 0.04 \\
\hline$K_{I}(\max )$ & 0.6 \\
\hline
\end{tabular}

